\title{
Reliability level research in distribution electrical networks of Irkutsk
}

\author{
Igor V. Naumov ${ }^{124}$, Elena V. Karpova ${ }^{1}$, Dmitriy N. Karamov ${ }^{13}$ \\ ${ }^{1}$ Irkutsk National Research Technical University, 83, Lermontov street, Irkutsk, 664074, Russia \\ ${ }^{2}$ Amur State University, 23 Ignatyevskoye Highway, Blagoveshchensk, 675027, Russia \\ ${ }^{3}$ Melentiev Energy Systems Institute of Siberian Branch of the Russian Academy of Science, 130, Lermontov street, Irkutsk, \\ 664033, Russia \\ ${ }^{4}$ Irkutsk State Agrarian University named after A.A. Ezhevsky, 1/1, Molodezhnaya street, Irkutsk district Molodezhny \\ settlement, 664038, Russia
}

\begin{abstract}
Forecasting of level of reliability of power supply of consumers is one of the major tasks at implementation of actions for improvement of operational characteristics of distribution electrical networks. On the one hand, assessment of damageability allows to develop a number of actions for increase in reliability of electric equipment and elements of electrical networks, with another, to create a stock of that equipment which is subject to risk of premature failure. The purpose of the present article is implementation of statistical assessment of damageability of basic elements of distribution electrical networks of $10 \mathrm{kV}$ on the basis of the predicted information on possible refusals in these networks. The main objectives for achievement of the specified purpose are: 1. Implementation of preventive assessment of refusals in electrical networks on the basis of data of dispatching magazines of observations; 2 . Statistical assessment of casual events of failures of electric equipment and detection of their laws of distribution.
\end{abstract}

\section{Introduction}

Breaks of supply of consumers with electric energy are rather frequent event having a wide range of social and economic consequences. At the same time the power supply breaks caused by the casual events having internal and external character result in the significant material damage exceeding damage from planned shutdowns [1].

For determination of level of reliability of power supply such indicator as SAIFI (System Average Interruption Frequency Index is the average frequency of emergence of damages to a system) - characterizing average of breaks in power supply in a year on one consumer is most often used. According to the experts, the average value of this index for a number of the European countries varies from 0.2 to 4.35 [2-4]. According to the Ministry of Energy of the Russian Federation, for Southern electrical networks (SEN) Irkutsk Electric Grid Company this indicator makes 0.31 [5]. For example, power system reliability index in the following countries has the mean values: Austria - 0,73; Great Britain - 0,53; Germany - 0,51; Norway - 1.59; Finland - 1.42.

The damages of the equipment of distribution networks and damage to networks of consumers caused by a number of the reasons are the main reasons for emergence of refusals. Therefore, forecasting of damageability of electric equipment of distribution networks is an important task at increase in level of reliability of power supply. Definition of the equipment subject to risk of damage allows to create the reserve necessary for reduction of the possible risks connected with breaks of power supply [6].

For formation of the most exact forecast of failures of electric equipment, it is necessary to define the law of distribution to which this type of shutdowns submits that demands use of rather difficult mathematical apparatus. Therefore for assessment of level of damageability of the equipment of distribution networks use of the specialized software is expedient.

\section{Object of research and description of the technique}

As an example we will consider data on refusals of power supply of consumers of Right-bank and Left-bank districts of Irkutsk. During work dispatching magazines of shutdowns of SEN Irkutsk Electric Grid Company for 2013-2017 were analysed [7]. Shutdowns are considered for the reasons, the most frequent of which are: damages to networks of the consumer; damages on complete transformer substations; wire breakage; damage of

professornaumov@list.ru 
support; damage of switching devices, insulators, dischargers and fuses. Also for each type of the reasons of shutdown of consumers time of a break of power supply and size of a underproduction of the electric power were defined. On the basis of the obtained data the forecast of level of damageability of an electrical network for 2017 with use of the Forecast-2+ program was carried out [8] and also the statistical analysis of data is carried out.

Let's make the analysis of the data obtained when using the «Forecast-2+» program, and we will define a forecast error. One of the most frequent reasons of shutdown of consumers is damage of wires that is caused with a big extent of networks of 6-10 kV [6]. According to the forecast, during the period from January to December, 2017 at the adopted exponential law of distribution (fig. 1) there were 1133 breaks of power supply connected with break and whipping of wires, however according to dispatching magazines only 587 shutdowns (table 1) were made. It says about unacceptability of this method of forecasting in the practical purposes when using limited quantity of basic data. However during the spring and summer period, with a large number of shutdowns (that is connected with carrying out repair work with soil opening), the average value of an error of forecasting does not exceed $50 \%$.

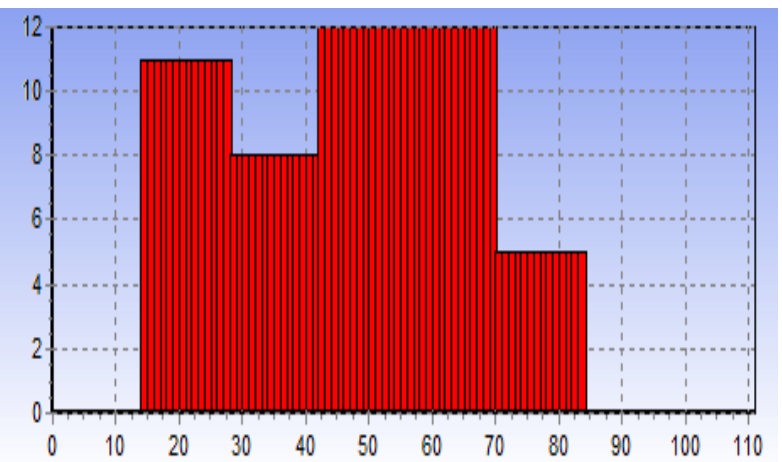

Fig.1. The law of distribution of probability of a break of power supply because of damages of wires.

\section{Numerical results}

Table 1 The summary table of number of shutdowns because of breaks and whipping of wires.

\begin{tabular}{|c|c|c|c|}
\hline Month & $\begin{array}{c}\text { Actual } \\
\text { number of } \\
\text { shutdowns }\end{array}$ & $\begin{array}{c}\text { "Forecast- } \\
2+"\end{array}$ & $\begin{array}{c}\text { Prediction } \\
\text { error, \% }\end{array}$ \\
\hline January & 19 & 53 & 178,95 \\
\hline February & 32 & 62 & 93,75 \\
\hline March & 24 & 70 & 191,67 \\
\hline April & 50 & 116 & 132,01 \\
\hline May & 63 & 76 & 20,63 \\
\hline June & 86 & 98 & 13,95 \\
\hline July & 94 & 125 & 32,98 \\
\hline August & 54 & 116 & 114,81 \\
\hline September & 59 & 90 & 52,54 \\
\hline October & 47 & 74 & 57,45 \\
\hline November & 28 & 81 & 189,29 \\
\hline December & 36 & 62 & 72,22 \\
\hline$\sum$ & 592 & 1023 & 72,80 \\
\hline
\end{tabular}

For implementation of the statistical analysis we will determine the probability of emergence of each of outcomes by the following expression:

$$
\mathrm{p}=\frac{\mathrm{n}_{\mathrm{i}}}{\mathrm{N}},
$$

where $n_{i}$ is quantity of outcomes number of shutdowns; $\mathrm{N}$ - total number of outcomes.

Calculation results are presented in table 2.

Table 2 The law of distribution of number of shutdowns because of damage of wires.

\begin{tabular}{|c|c|c|}
\hline Outcome & $\begin{array}{l}\text { Number of } \\
\text { outcomes }\end{array}$ & Probability \\
\hline 17 & 1 & 0,020833 \\
\hline 18 & 1 & 0,020833 \\
\hline 19 & 2 & 0,041667 \\
\hline 22 & 2 & 0,041667 \\
\hline 23 & 1 & 0,020833 \\
\hline 25 & 1 & 0,020833 \\
\hline 26 & 3 & 0,0625 \\
\hline 29 & 2 & 0,041667 \\
\hline 32 & 1 & 0,020833 \\
\hline 34 & 1 & 0,020833 \\
\hline 36 & 2 & 0,041667 \\
\hline 38 & 1 & 0,020833 \\
\hline 41 & 1 & 0,020833 \\
\hline 42 & 1 & 0,020833 \\
\hline 43 & 1 & 0,020833 \\
\hline 44 & 1 & 0,020833 \\
\hline 48 & 1 & 0,020833 \\
\hline 50 & 1 & 0,020833 \\
\hline 51 & 2 & 0,041667 \\
\hline 53 & 2 & 0,041667 \\
\hline 54 & 1 & 0,020833 \\
\hline 55 & 2 & 0,041667 \\
\hline 56 & 1 & 0,020833 \\
\hline 59 & 1 & 0,020833 \\
\hline 60 & 1 & 0,020833 \\
\hline 61 & 1 & 0,020833 \\
\hline 62 & 2 & 0,041667 \\
\hline 64 & 1 & 0,020833 \\
\hline 66 & 1 & 0,020833 \\
\hline 67 & 2 & 0,041667 \\
\hline 69 & 2 & 0,041667 \\
\hline 72 & 1 & 0,020833 \\
\hline 74 & 1 & 0,020833 \\
\hline 78 & 2 & 0,041667 \\
\hline 87 & 1 & 0,020833 \\
\hline
\end{tabular}

The mathematical expectation, dispersion and mean square deviations for the shutdowns connected with damage of wires respectively are equal:

$$
\begin{aligned}
& \mathrm{M}\left(\mathrm{n}_{\mathrm{i}}\right)=\sum \mathrm{n}_{\mathrm{i}} \cdot \mathrm{p}_{\mathrm{i}}=47,25 ; \\
& \mathrm{D}\left(\mathrm{n}_{\mathrm{i}}\right)=\mathrm{M}\left(\mathrm{n}_{\mathrm{i}}^{2}\right)-\left(\mathrm{M}\left(\mathrm{n}_{\mathrm{i}}\right)\right)^{2}=354,48 ; \\
& \sigma=\sqrt{\mathrm{D}\left(\mathrm{n}_{\mathrm{i}}\right)}=18,828 .
\end{aligned}
$$

On the basis of the received results we will construct a polygon of distribution (fig. 2). 


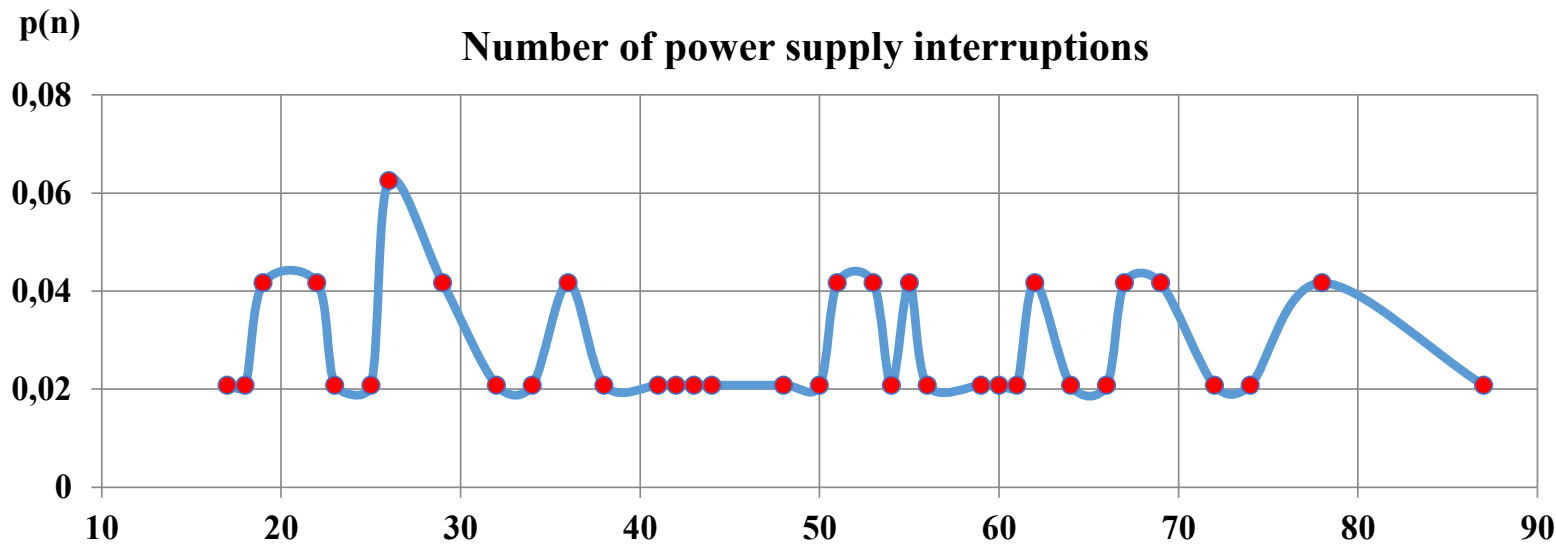

Fig. 2 Function of distribution of number of the shutdowns made because of damage of wires.

According to the built ground the received function of distribution does not correspond to the law of distribution of random variables adopted when forecasting number of shutdowns with use SW "Forecast-2+" that explains an essential error of the forecast and represents the uniform law of distribution. Such result cannot be explained with the fact that the number of the shutdowns made because of damage of wires is connected with physical wear of the equipment, and is caused by a number of casual events, such as various weather phenomena, work with soil opening and another [9].

We will carry out the similar analysis for refusals because of damage of insulators. Climatic influences, defects of a design, production and installation, aging of materials, etc. [10] can be the reasons of damages of insulators.

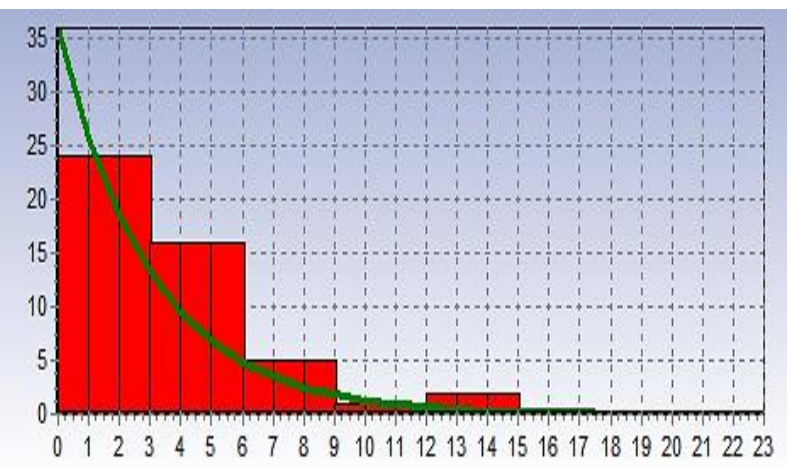

Fig. 3 The law of distribution of probability of a break of power supply because of damages of insulators adopted ON "Forecast-2+".

In this case the exponential law of distribution (fig. 3) adopted to calculation SW "Forecast-2+" allowed to carry out the forecast of level of damageability of insulators with significantly smaller mistake, than when forecasting damageability of wires (table 3 ). In spite of the fact that forecasting on months is not always carried out with a sufficient accuracy, the error at implementation of the annual forecast made only $2 \%$. Thus, we will apply the algorithm of forecasting of level of damageability of insulators used in SW "Forecast-2+" to planning of the actions directed to minimization of damage from power supply breaks.
Table 3. The summary table of number of shutdowns because of damage of insulators.

\begin{tabular}{|c|c|c|c|}
\hline Month & $\begin{array}{c}\text { Actual } \\
\text { number of } \\
\text { shutdowns }\end{array}$ & $\begin{array}{c}\text { "Forecast- } \\
2+"\end{array}$ & $\begin{array}{c}\text { Prediction } \\
\text { error, \% }\end{array}$ \\
\hline January & 1 & 2 & 200 \\
\hline February & 0 & 1 & 100 \\
\hline March & 4 & 2 & -200 \\
\hline April & 3 & 3 & 0 \\
\hline May & 8 & 3 & $-166,67$ \\
\hline June & 7 & 3 & $-133,33$ \\
\hline July & 8 & 6 & $-33,33$ \\
\hline August & 10 & 9 & $-11,11$ \\
\hline September & 3 & 6 & 200 \\
\hline October & 1 & 2 & 200 \\
\hline November & 0 & 5 & 500 \\
\hline December & 0 & 2 & 200 \\
\hline$\sum$ & 45 & 44 & $-2,27$ \\
\hline
\end{tabular}

Table 4 The law of distribution of number of shutdowns because of damage of insulators.

\begin{tabular}{|c|c|c|}
\hline Outcome & $\begin{array}{c}\text { Number of } \\
\text { outcomes }\end{array}$ & Probability \\
\hline 0 & 10 & 0,208333 \\
\hline 1 & 8 & 0,166667 \\
\hline 2 & 6 & 0,125 \\
\hline 3 & 10 & 0,208333 \\
\hline 4 & 5 & 0,104167 \\
\hline 5 & 1 & 0,020833 \\
\hline 6 & 3 & 0,0625 \\
\hline 8 & 2 & 0,041667 \\
\hline 9 & 1 & 0,020833 \\
\hline 12 & 1 & 0,020833 \\
\hline 14 & 1 & 0,020833 \\
\hline
\end{tabular}

The mathematical expectation, dispersion and rootmean-square deviation for the shutdowns connected with damage of insulators respectively are equal:

$$
\begin{aligned}
& M\left(n_{i}\right)=\sum n_{i} \cdot p_{i}=3 \\
& D\left(n_{i}\right)=M\left(n_{i}^{2}\right)-\left(M\left(n_{i}\right)\right)^{2}=9,417 \\
& \sigma=\sqrt{D\left(n_{i}\right)}=3,069
\end{aligned}
$$

On the basis of the received results we will construct a polygon of distribution (fig. 4). 


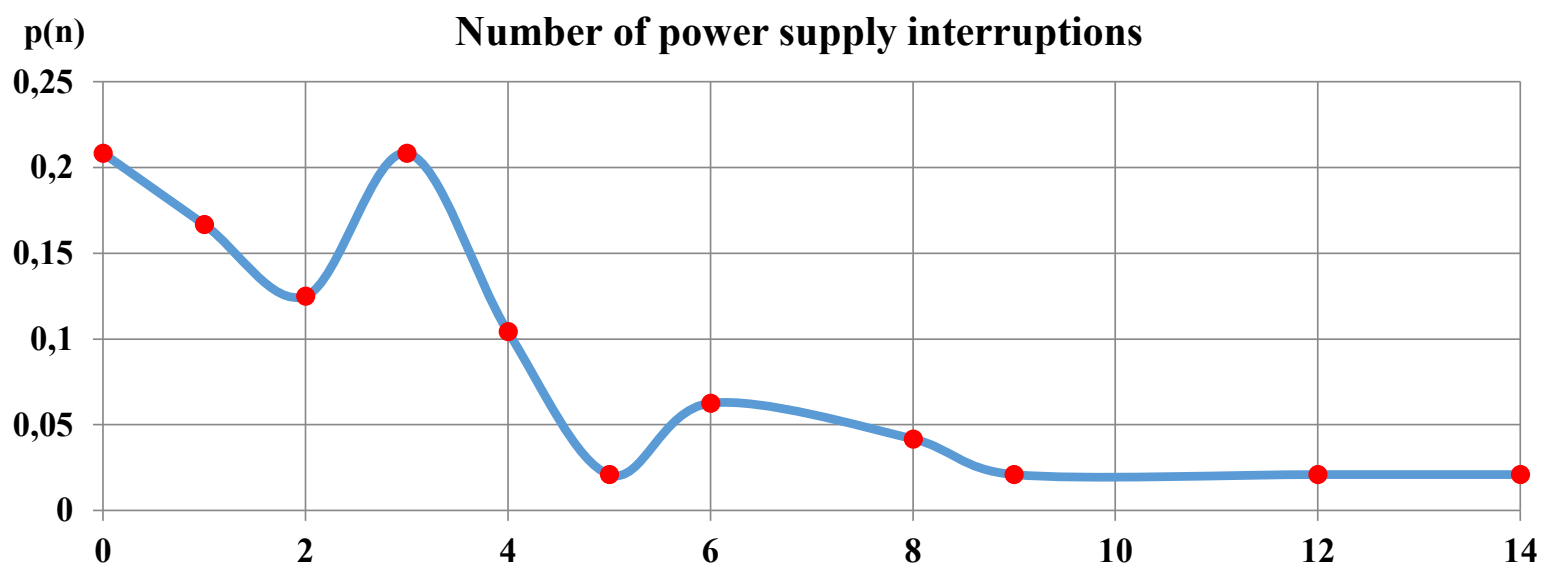

Fig. 4. The ground of distribution of number of the shutdowns made because of damage of insulators.

According to the built ground the received distribution function more corresponds to the exponential law of distribution of random variables that explains a low error of forecasting software "Forecast-2+". Using the obtained data, we will define function of distribution and we will construct its schedule (fig. 5):

$$
\mathrm{p}(\mathrm{n})=\frac{1}{\mathrm{M}\left(\mathrm{n}_{\mathrm{i}}\right)} \cdot \mathrm{e}^{-\frac{1}{\mathrm{M}\left(\mathrm{n}_{\mathrm{i}}\right)} \cdot \mathrm{n}}=0,333 \cdot \mathrm{e}^{-0,333 \cdot \mathrm{n}} .
$$

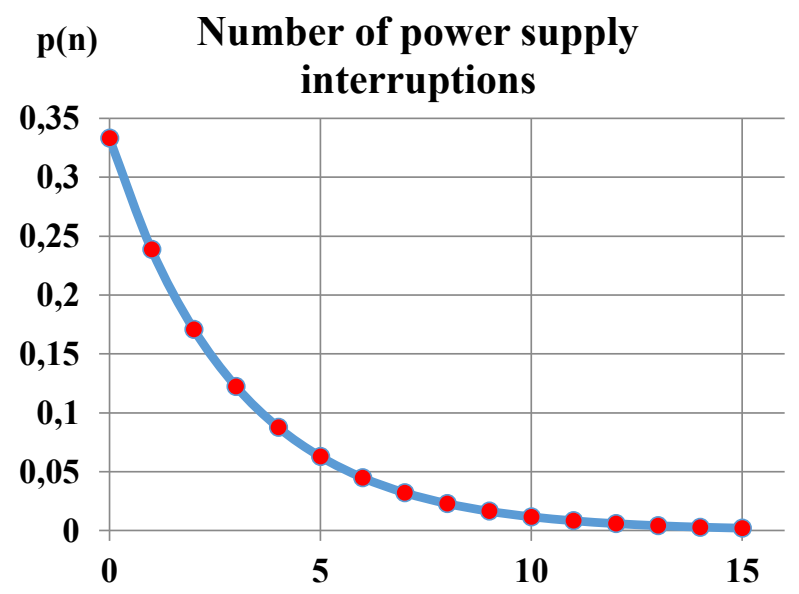

Fig. 5. The law of distribution of probability of a break of power supply because of damages of insulators received by the statistical analysis.

Besides, this software also allows to make with various degree of accuracy the forecast of shutdowns because of unauthorized intervention of the person in work of an electrical network, damages of dischargers, safety locks, the switching equipment and complete transformer substations.

\section{Conclusions}

As a result of the carried-out analysis of data of the forecast it was defined that the damageability level assessment algorithm used in the software "Forecast-2" is suitable for use of this algorithm for determination of size of a reserve of the equipment subject to damages more.

However for the reasons of shutdown of consumers which in a smaller measure are defined by physical wear of the equipment and depend on accidental influences, such as weather phenomena, but have no exponential

Nature of distribution, the forecast has a big mistake and demands adjustment with application of the statistical analysis of data of dispatching magazines for definition of the real law of distribution.

\section{References}

1. Gulidov S.S. GAU Oryol Bulletin, 12(1), 144-146 (2012).

2. Serena Hesmondhalgh, William P. Zarakas, Toby Brown. The Brattle Group, Inc, 190 (2012).

3. StatNet. Arasstatistikk 2007-2016. Available at: http://www.statnett.no/Kraftsystemet/Nedlastingsse nter/Feilstatistikk

4. Council of European Energy Regulators. CEER Benchmarking Report 6.1 on the Continuity of Electricity supply: Data update. Issued by Council of European Energy Regulators ASBL. Brussels: CEER.

5. Protocol of the All-Russian meeting on the course to preparation for OZP 2017-2018 (No. AN-480 of the ave. of 06.10.2017)

6. Karamov D.N., Naumov I.V., Perzhabinsky S.M. Bulletin of the Tomsk Polytechnic University. Geo Assets Engineering, 329(7), 116-130.

7. Report of emergency shutdowns of branch of the southern electrical networks of JSC Irkutsk Electric Grid Company, 2013-2017.

8. Naumov I.V., Lanin A.V. "Forecast-2+" / State registration of computer program No. 2011618014 of October 12, 2011.

9. Doronina O.I., Shevchenko N.Yu., Bakhtiarov K.N The International magazine of applied and basic researches, 9(2), 226-230 (2015).

10. Rybakov L.M., Ivanova Z.G. Bulletin of the Chuvash University. 1, 104-110 (2015). 